\title{
Preservation of Biologically Active Compounds and Nutritional Potential of Quick-Frozen Berry Fruits of the Genus Rubus
}

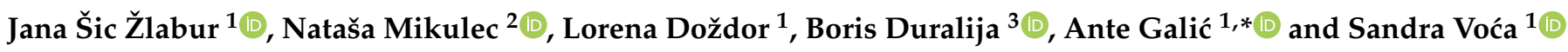 \\ 1 Department of Agricultural Technology, Storage and Transport, Faculty of Agriculture, University of Zagreb, \\ Svetošimunska Cesta 25, 10000 Zagreb, Croatia; jszlabur@agr.hr (J.Š.Ž.); lorenadozdor@hotmail.com (L.D.); \\ svoca@agr.hr (S.V.) \\ 2 Department of Dairy Science, Faculty of Agriculture, University of Zagreb, Svetošimunska Cesta 25, \\ 10000 Zagreb, Croatia; nmikulec@agr.hr \\ 3 Department of Pomology, Faculty of Agriculture, University of Zagreb, Svetošimunska Cesta 25, \\ 10000 Zagreb, Croatia; bduralija@agr.hr \\ * Correspondence: agalic@agr.hr
}

Citation: Žlabur, J.Š.; Mikulec, N.; Doždor, L.; Duralija, B.; Galić, A.; Voća, S. Preservation of Biologically Active Compounds and Nutritional Potential of Quick-Frozen Berry Fruits of the Genus Rubus. Processes 2021, 9, 1940. https://doi.org/ $10.3390 /$ pr9111940

Academic Editor: Yonghui Li

Received: 17 September 2021

Accepted: 26 October 2021

Published: 29 October 2021

Publisher's Note: MDPI stays neutral with regard to jurisdictional claims in published maps and institutional affiliations.

Copyright: (c) 2021 by the authors. Licensee MDPI, Basel, Switzerland. This article is an open access article distributed under the terms and conditions of the Creative Commons Attribution (CC BY) license (https:/ / creativecommons.org/licenses/by/ $4.0 /)$.

\begin{abstract}
Cryoprotective freezing methods are increasingly being developed and used as an effective means of protecting valuable bioactive compounds in processed berry fruits. The quick-freezing method allows the bioactive compounds in the plant material to be preserved over a longer period of time, thus providing a high-quality product with significant antioxidant capacity. The aim of this study was to determine the effects of the quick-freezing method on physico-chemical properties and bioactive compounds content of fruits in three soft fruit species: tayberry, raspberry, and blackberry, and to evaluate the stability of specific phytochemicals during the three-month storage period. The freezing method had a significant effect on the physicochemical properties with a significantly less drip loss observed after thawing in fruit frozen by quick-freezing (at $-34^{\circ} \mathrm{C}$ for $25 \mathrm{~min}$ ) compared to fruit frozen classically $\left(-18^{\circ} \mathrm{C}\right.$ to $24 \mathrm{~h}$ ). The color of quick-frozen fruits also changed significantly less compared to fresh fruits. Of the bioactive compounds analyzed, it should be noted that there was a significantly lower loss of ascorbic acid recorded during quick-freezing. On average, the quick-frozen fruits contained $28 \%$ more ascorbic acid than the classical frozen fruits. In general, the quick-freezing procedure contributed to a better preservation of total polyphenolic compounds and anthocyanins, and thus berry fruits also showed higher values of antioxidant capacity during quick freezing than during the classical procedure. During the storage period of three months, a decrease in the content of all the bioactive compounds studied was observed, although it should be emphasized that this loss during storage was not as pronounced in fruits frozen by the quick-freezing method as in classically frozen fruits. It can be concluded that the quick-freezing contributes significantly to the preservation of valuable bioactive compounds of berries and that this processing method can be considered important for maintaining the nutritional properties of berry fruits.
\end{abstract}

Keywords: berry fruits; phytochemicals; phenols; nutritional quality; antioxidant capacity; storage; freezing method

\section{Introduction}

Water is one of the most important components of food and, as a key medium or environmental factor, is involved in the formation of almost all chemical, biological, and physical processes. After harvesting the raw material, water content is one of the most important limiting factors to maintain the quality of the raw material, i.e., the fresh food intended for consumption. Indeed, free moisture and numerous enzymes active in postharvest processes can significantly affect the content of biologically active compounds such as phenols, vitamins, and other phytochemicals and, above all, cause their degradation, thus reducing the nutritional potential and the overall quality of the raw materials [1]. Berry fruits are characterized precisely by their favorable nutritional composition; they are rich 
in a specialized metabolites or phytochemicals with strong antioxidant activity and thus have a very important beneficial effect on human health. Compounds such as polyphenols (flavonoids, phenolic acids, flavonols), anthocyanins (cyanidin, pelargonidin), quercetin, rutin, vitamins (vitamin C), and carotenoids (zeaxanthin, alpha-carotene, beta-carotene) have a strong positive influence on human health [2], and are abundant in berry fruits species, have anti-inflammatory, anti-allergic, and anti-cancer effects precisely because of the significant antioxidant action, i.e., inhibition of oxygen reactive species (ROS) in human cells, and are therefore effective in the prevention of many chronic diseases [2-7].

The berry fruits are characterized by a high-water content (as well as sugar) and require specific post-harvest conditions that result in slowing down the biochemical processes by enzymes and inhibit the growth of microorganisms, thus ensuring a longer shelf life and generally a longer product life. Precisely because of their high perishability and seasonality, the berry fruits except in fresh state, whose shelf life is relatively short, are often processed or subjected to processing operations that collectively remove large amounts of water, slowing and/or stopping undesirable processes that lead to the degradation of the nutritional quality of the product. One of the most efficient processes for the long-term preservation and storage of fruits, which has a minimal impact on the nutritional quality of the food, is freezing. In general, lowering the temperature below the freezing point of a raw material allows the inhibition of many metabolic processes in the fruit, slows down the growth kinetics of microorganisms, and ultimately prevents the degradation reactions of important phytochemicals. Main limiting factor of the freezing process, as a result of water mobilization by crystallization in the form of ice crystals, is a reduction in the amount of water, resulting in reduced product freshness, crystallization of amorphous solutes, which can lead to the degradation of some important bioactive compounds and mainly affect the deformation of the texture and structure of the product and deteriorate the characteristic color of the product. This is strongly influenced by the size and position of the ice crystals formed, which, depending on the type of freezing process applied, may result in greater or weaker damage of cell membranes and degradation of the physical structure, which ultimately manifests itself in reduced product quality after thawing [8,9]. On the other hand, some authors state [8-11] that certain freezing processes show positive effects on the functional properties of the raw material, as freezing can favor the release of bound compounds such as phenolic acids and anthocyanins and thus the release of bioactive compounds.

Precisely, because of all this, more and more cryoprotection methods are being developed, i.e., the use of much lower freezing temperatures (cryogenic), which make it possible to reach the freezing point of the raw material in a very rapid time, just a few seconds. In fact, the use of quick-freezing methods allows the formation and growth of smaller ice crystals in greater numbers, which ultimately do not cause excessive damage to the plant cell and, consequently, to other physical and chemical properties of the product, as is the case with classical freezing methods $\left(-18{ }^{\circ} \mathrm{C}\right.$, over $\left.24 \mathrm{~h}\right)$. Depending on the refrigerant used (cryogenic gas), quick-freezing processes can last only a few seconds to a few minutes (e.g., using liquid nitrogen at temperatures down to $-196{ }^{\circ} \mathrm{C}$ only a few seconds) [9,12-15]. It should also be emphasized that the authors point out that foods frozen using quick-freezing methods have a longer shelf life, i.e., their nutritional quality is not affected as much during the storage period as is the case with foods frozen using conventional methods [9,15-18]. Based on all the above, the aim of this study was to determine the effect of the quick-freezing method on bioactive compounds content in three berry fruit species: tayberry (Rubus fruticosus $\times$ idaeus), raspberry (Rubus idaeus), and blackberry (Rubus fruticosus agg.), and to evaluate the stability of specific phytochemicals during the storage period of the frozen fruits. 


\section{Materials and Methods}

\subsection{Plant Material}

The following berry fruit species were conducted in the study: tayberry (Rubus fruticosus $\times$ Rubus idaeus), raspberry (Rubus idaeus) cv. 'Tulameen', and blackberry (Rubus fruticosus agg.) cv. 'LochNess'. All berry fruit species were grown and harvested on the family farm in Koprivnica (Croatia) in July at the optimal time of ripening. The berry fruits were harvested by hand, in the early morning hours during dry weather. Only healthy fruits without visible signs of damage were randomly collected in PET containers, with a total weight of fruits per container of $125 \mathrm{~g}$. A total of 7 PET containers were harvested for each berry fruit species. Immediately after harvesting, the fruits were transported to the Department of Agricultural Technology, Storage and Transport, Faculty of Agriculture, University of Zagreb, where they were stored in a refrigerator $\left(4{ }^{\circ} \mathrm{C}, 87 \%\right.$ humidity) until the planned freezing procedures (1 day). In addition, a part of the fruit was separated from each berry species in order to perform chemical analysis of the fresh fruit.

\subsection{Freezing and Storage of Frozen Fruits}

The fruits were first selected for freezing, while those with possible mechanical damage or visible signs of spoilage were removed. Only healthy fruits were then washed under a gentle stream of water. After washing, fruits were air-dried to remove excess water and separated for classical freezing (CLAS) and quick-freezing (QF). For the needs of classical freezing, berries were packed in PET plastic bags, about 20 fruits for each species in a total of 5 replicates. Classic freezing was performed at $-18{ }^{\circ} \mathrm{C}$ for $24 \mathrm{~h}$ in a classic freezer (Lth 1, Gorenje, Ljubljana, Slovenia). For the purpose of quick-freezing, fruits were placed in plastic containers (average size $142 \times 94 \times 35 \mathrm{~mm}$ ) with openings of $50 \mathrm{~mm}$ diameter, a total of 15 fruits per container in 5 replicates (each species had 5 replicants for freezing). The quick-freezing procedure was performed in a shock freezer (Tecnomac Sf 1, Castelfranco Veneto, Italy) at $-34^{\circ} \mathrm{C}$ for 25 min using carbon dioxide as refrigerant fluid (2200 g-R404A, GWP3922). The experimental design of berry fruits freezing procedures is shown in Table 1.

Table 1. The experimental plan for fruit-freezing of different berry species.

\begin{tabular}{ccccccc}
\hline Species & Freezing Method & Temperature $\left({ }^{\circ} \mathbf{C}\right)$ & Time $(\mathbf{m i n})$ & Equipment & Refrigeration Fluid & Treatment \\
\hline Tayberry & classical & -18 & 1440 & classic freezer & R600a & Tay-CLAS \\
Tayberry & quick-freeze & -34 & 25 & shock freezer & R404A & Tay-QF \\
Raspberry & classical & -18 & 1440 & classic freezer & R600a & Rsp-CLAS \\
Raspberry & quick-freeze & -34 & 25 & shock freezer & R404A & Rsp-QF \\
Blackberry & classical & -18 & 1440 & classic freezer & R600a & Blc-CLAS \\
Blackberry & quick-freeze & -34 & 25 & shock freezer & R404A & Blc-QF \\
\hline
\end{tabular}

Tay-CLAS-tayberry classical freezing; Tay-QF-tayberry quick-freezing; Rsp-CLAS-raspberry classical freezing; Rsp-QF-raspberry quick-freezing; Blc-CLAS-blackberry classical freezing; Blc-QF- blackberry quick-freezing.

The time required to completely freeze the fruits by classical freezing was $24 \mathrm{~h}$ (1440 $\mathrm{min}$ ), while only $25 \mathrm{~min}$ was required in quick-freezing. Thawing was carried out at a temperature of $4{ }^{\circ} \mathrm{C}$ for both classically and quick-frozen fruits, and lasted for classic frozen fruits approximately $20 \mathrm{~h}$, while for quick-frozen, it was $90 \mathrm{~min}$. Storage of frozen fruits, both classic and quick-frozen, was carried out under the same conditions, i.e., at $-18^{\circ} \mathrm{C}$ for a total duration of 3 months.

\subsection{Drip Loss Determination}

To determine the loss of cell juice (water) during thawing, the fruits were weighed immediately after freezing (m1) and after thawing (m2) and calculated according to Equation (1) [19].

$$
\text { Drip loss }(\%)=\frac{\mathrm{m} 1-\mathrm{m} 2}{\mathrm{~m} 1} \times 100
$$




\subsection{Determination of Physico-Chemical Properties}

All analyzes were performed on fresh berry fruits, while frozen fruits were thawed before analysis. For chemical analysis, both fresh and thawed berry fruits were homogenized and a uniform sample was prepared according to the procedure for each specific analysis. The physico-chemical parameters determined in berry fruits by standard laboratory procedures according to [20] were: total dry matter content (DM, \%) by drying at $105^{\circ} \mathrm{C}$ to constant mass, total soluble solids (TSS, \%) by digital refractometer (Mettler Toledo, Refracto 30PX, Greifensee, Switzerland), total acidity (TA, \%) by potentiometric titration, $\mathrm{pH}$ value by digital $\mathrm{pH}$ meter (Mettler Toledo, SevenMulti, Greifensee, Switzerland). For the purposes of color determination of fresh and frozen berry fruits, the total number of 30 fruits of each berry species were selected and by colorimeter (ColorTec $\mathrm{PCM}+$, Meschede, Germany) according to the CIELAB method's chromaticity parameters $\left(L^{*}, a^{*}, b^{*}, C, h^{\circ}\right)$ were measured.

\subsection{Determination of Specialized Metabolites Content}

From the group of specialized metabolites, the following were determined: ascorbic acid (AsA) content by titration with 2,6-dichloroindophenol (DKF) according to [21]. AsA was isolated from fresh and frozen berry fruits by homogenizing $10 \mathrm{~g} \pm 0.01$ of the plant material with $100 \mathrm{~mL}$ of $2 \%(v / v)$ oxalic acid. The prepared solution was allowed to stand for about $20 \mathrm{~min}$, filtered through Whatman filter paper, and the filtrate was obtained in a volume of $10 \mathrm{~mL}$. The obtained $10 \mathrm{~mL}$ filtrate was titrated with freshly prepared 2,6-dichloroindophenol (DKF) until a pink color appeared. The final AsA content was calculated according to Equation (2) and expressed as $\mathrm{mg} / 100 \mathrm{~g}$ fresh weight (fw) for samples in fresh state and as $\mathrm{mg} / 100 \mathrm{~g}$ dry weight $(\mathrm{dw})$ for frozen and stored samples.

$$
\operatorname{AsA}(\mathrm{mg} / 100 \mathrm{~g} \mathrm{fw})=\frac{\mathrm{V}(\mathrm{mL}) \times \mathrm{F}}{\mathrm{D}} \times 100
$$

where, V-volume of DKF (mL); F-factor of DKF; D—sample mass used for titration.

From the group of polyphenolic compounds, total phenolics (TPC), total flavonoids (TFC), and total non-flavonoids (TNFC) were determined. The values of all the above polyphenolic compounds were determined spectrophotometrically (Shimadzu, UV 1650 PC) according to a method described by Ough and Amerine [22]. The method is based on a color reaction that phenols develop with Folin-Ciocalteu reagent, measured at $750 \mathrm{~nm}$. The isolation of polyphenolic compounds ( $10 \mathrm{~g} \pm 0.01$ of plant material) was carried out with total of $100 \mathrm{~mL}$ of $80 \% \mathrm{EtOH}(v / v)$ by heating to the boiling point with reflux for total time of $20 \mathrm{~min}$. The extract thus prepared was used for the reaction with the reagent Folin-Ciocalteu as follows: $0.5 \mathrm{~mL}$ of ethanolic extract, $30 \mathrm{~mL}$ of distilled water $\left(\mathrm{dH}_{2} \mathrm{O}\right)$, $2.5 \mathrm{~mL}$ of the prepared reagent Folin-Ciocalteu $\left(1: 2\right.$ with $\left.\mathrm{dH}_{2} \mathrm{O}\right)$, and $7.5 \mathrm{~mL}$ of saturated sodium carbonate solution $\left(\mathrm{Na}_{2} \mathrm{CO}_{3}\right)$ were added; the flask $(50 \mathrm{~mL})$ was filled to the mark with $\mathrm{dH}_{2} \mathrm{O}$ and the prepared sample was allowed to stand at room temperature for $2 \mathrm{~h}$ with intermittent shaking. The same ethanolic extracts prepared for TPC determination were used for TNFC content determination, while TNFC separation was performed according to the following procedure: $10 \mathrm{~mL}$ of the ethanolic extract was added to the $25 \mathrm{~mL}$ capacity volumetric flask, then $5 \mathrm{~mL}$ of $\mathrm{HCl}(1: 4, v / v)$ and $5 \mathrm{~mL}$ of formaldehyde were added. The prepared samples were blown with nitrogen $\left(\mathrm{N}_{2}\right)$ and left for $24 \mathrm{~h}$ at room temperature in a dark place. After $24 \mathrm{~h}$, the same Folin-Ciocalteu reaction was performed as for TPC. The absorbance of blue color in both TPC and TNFC reactions was measured spectrophotometrically at $750 \mathrm{~nm}$ using distilled water as a blank. Gallic acid and catechin were used as external standards and the concentration of TPC and TNFC content was expressed as mg GAE/100 $\mathrm{g}$ fresh weight ( $\mathrm{fw}$ ) and for the frozen and stored samples as mg GAE/100 mg dry weight (dw). The TFC content was mathematically expressed as the difference between total phenols and non-flavonoids. Total anthocyanin content (TAC) was determined according to the bisulfite bleaching method described by Ough and Amerine [22]. Plant material (2 $\mathrm{g} \pm 0.01)$ was weighed into a cuvette volume of $50 \mathrm{~mL}$, to 
which $2 \mathrm{~mL}$ of $0.1 \% \mathrm{HCl}$ (diluted with $96 \% \mathrm{EtOH}$ ) and $40 \mathrm{~mL}$ of $2 \% \mathrm{HCl}(v / v)$ were added. The prepared samples were centrifuged at $4500 \mathrm{rpm}$ for $10 \mathrm{~min}$. After centrifugation, $10 \mathrm{~mL}$ of the supernatant was separated into one test tube and $10 \mathrm{~mL}$ into another test tube. To the first test tube, $4 \mathrm{~mL}$ of $\mathrm{dH}_{2} \mathrm{O}$ was added (blank), while to the second test tube, $4 \mathrm{~mL}$ of a freshly prepared solution of $15 \%$ sodium bisulfite $\left(\mathrm{NaHSO}_{3}, v / v\right)$ was added. The samples thus prepared were allowed to stand in the test tubes for $15 \mathrm{~min}$, while thereafter the absorbances (A1 for the blank and A2 for the reaction with bisulfite) were measured spectrophotometrically at $520 \mathrm{~nm}$ using $2 \% \mathrm{HCl}(v / v)$ as a blank. The final anthocyanin content (TAC) was calculated from the difference in absorbance (A1-A2) multiplied by the molar mass of the most abundant anthocyanin and expressed as $\mathrm{mg} / \mathrm{kg}$ fresh weight (fw) and for the frozen and stored samples as $\mathrm{mg} / \mathrm{kg}$ dry weight $(\mathrm{dw})$.

\subsection{Determination of Antioxidant Capacity}

The antioxidant capacity assay was performed with an ABTS radical cation (2,2'azinobis (3-ethylbenzothiazoline-6-sulfonic acid)) and determined spectrophotometrically according to the method described by Miller et al. [23]. The same ethanolic extracts were used as for the polyphenolic compounds. The Trolox was used as antioxidant standard (6-Hydroxy-2,5,7,8-tetramethylchroman-2-carboxylic acid, Sigma-Aldrich, St. Louis, MO, USA) both for the preparation of the stock solution and appropriate dilutions to create the calibration curve. $5 \mathrm{~mL}$ of ABTS solution $(7 \mathrm{mM})$ and $88 \mathrm{~mL}$ of potassium persulfate solution $(140 \mathrm{mM})$ were mixed and left in the dark at room temperature for $16 \mathrm{~h}$ to obtain an ABTS radical (ABTS•1). On the day of analysis, a 1\% ABTS•1 solution (in 96\% EtOH) was prepared. A total of $160 \mu \mathrm{L}$ of the extract was directly injected into the cuvette and mixed with $2 \mathrm{~mL}$ of stable ABTS•1 and the absorbance was measured at $734 \mathrm{~nm}$ using $96 \%$ $\mathrm{EtOH}$ as a blank. Final results were expressed as $\mu \mathrm{mol} \mathrm{TE} / \mathrm{L}$.

\subsection{Statistical Analysis}

The data obtained were analyzed using SAS ${ }^{\circledR}$ version 9.3 [24]. One-way analysis ANOVA was used to determine the significance of differences within the berry species in fresh state. Freezing treatments were arranged in a randomized complete block design and all laboratory analyzes were performed in triplicate. A generalized linear model (PROC GLM) with replicates and interactions of berry species (tayberry, raspberry, blackberry), freezing method (classic, quick-freezing) and storage was used for the analysis. In both analyzes, means were compared using $t$-test (Least Significant Difference, LSD) and considered significantly different at $p \leq 0.01$. In addition to the results, the tables show different letters, indicating significant statistical differences between the different treatments at $p \leq 0.0001$. The average deviation of the results from the mean for each parameter studied with the standard deviation values are also indicated.

\section{Results and Discussion}

\subsection{Physico-Chemical Properties, Bioactive Compounds Content, and Antioxidant Capacity of} Fresh Berry Species

Berries are popular fruits mainly because of their excellent taste and aroma, but also because of their rich content of specialized metabolites, bioactive compounds, such as anthocyanins, flavonoids, phenolic acids, ellagitannins, etc. Due to their valuable nutritional composition and phytochemical content, berry fruits show numerous functional properties, ranging from antioxidant, antimicrobial, anti-inflammatory, to anticancer activities, thus strongly contributing to human health and representing a valuable nutritional source $[2,25,26]$. Due to specific physico-chemical parameters, berry fruits are often a valuable raw material for processing into various products such as juices, jams, jellies, syrups, dried fruits, etc., in addition to being eaten fresh. Tables 2 and 3 show the basic physico-chemical properties and bioactive compounds content of selected berry fruits in the fresh state. Highly significant statistical differences were found between different berry species for all analyzed physico-chemical parameters. Berry fruits are characterized by 
high water content, therefore post-harvest procedures and manipulations from harvest to storage and marketing are often very difficult and demanding. Depending on the species and cultivar, the average water content of berry fruits is in the range of $80-85 \%[27,28]$, and generally depends mainly on pedoclimatic conditions, cultivation method, and agrotechnical practices, as well as genetic characteristics. According to the results within this study, the highest total dry matter content (DM) was found for both raspberry and blackberry (average $15.71 \%$ ), while a slightly lower DM content was determined in tayberry fruit, about $8 \%$ lower compared to raspberry and blackberry. In addition to water content, berry fruits are also characterized by their high sugar and total acid content, the ratio of which is important for the formation of the final taste, which is why these fruits are so popular for fresh consumption. The total soluble solids content (TSS) was similar in all three species studied, the highest being found in blackberry $(12.23 \%)$ and the lowest in tayberry $(11.67 \%)$. The total acidity content (TA) varied in the range from $1.07 \%$ in blackberry to $1.73 \%$ in raspberry. Due to the relatively high TA content, low $\mathrm{pH}$ values were expected. The average $\mathrm{pH}$ value obtained in the analyzed berry species was 3.13 , with the lowest value recorded in raspberry, the species with the highest TA value, while the highest $\mathrm{pH}$ value was recorded in tayberry. The obtained values of the analyzed physico-chemical parameters of the studied berry species are generally in agreement with other literature citations [27-29] with a deviation in the TSS content of tayberry. Pantelidis [27] stated an average TSS value of $6 \%$, which is a significant difference from the data obtained in this study $(11.67 \%)$. The reason may be the factors already mentioned, primarily the pedoclimatic characteristics of the cultivation area, but also the agrotechnical practices applied during cultivation (fertilization, irrigation, pruning, etc.).

Table 2. Physico-chemical properties of fresh berry fruits.

\begin{tabular}{ccccc}
\hline Species & DM (\%) & TSS (\%) & TA (\%) & pH \\
\hline Tayberry & $14.56^{\mathrm{b}} \pm 0.38$ & $11.67^{\mathrm{b}} \pm 0.29$ & $1.12^{\mathrm{b}} \pm 0.03$ & $3.25^{\mathrm{a}} \pm 0.03$ \\
Raspberry & $15.65^{\mathrm{a}} \pm 0.36$ & $12^{\mathrm{ab}} \pm 0.1$ & $1.73^{\mathrm{a}} \pm 0.006$ & $3^{\mathrm{c}} \pm 0.001$ \\
Blackberry & $15.77^{\mathrm{a}} \pm 0.39$ & $12.23^{\mathrm{a}} \pm 0.29$ & $1.07^{\mathrm{c}} \pm 0.02$ & $3.14^{\mathrm{b}}$ \\
ANOVA & $p \leq 0.0142$ & $p \leq 0.0405$ & $p \leq 0.0001$ & $p \leq 0.0001$ \\
\hline
\end{tabular}

DM-total dry matter content; TSS—total soluble solids content; TA-total acid content. Results are expressed as mean \pm standard deviation. Different letters indicate significant differences between mean values.

Table 3. Chromatic parameters of fresh berry fruits.

\begin{tabular}{cccccc}
\hline Species & $\mathbf{L}^{*}$ & $\mathbf{a}^{*}$ & $\mathbf{b}^{*}$ & $\mathbf{C}$ & $\mathbf{h}^{\circ}$ \\
\hline Tayberry & $23.2^{\mathrm{b}} \pm 0.67$ & $18.51^{\mathrm{b}} \pm 2.37$ & $4.01^{\mathrm{b}} \pm 1.27$ & $18.97^{\mathrm{b}} \pm 2.95$ & $11.88^{\mathrm{b}} \pm 1.93$ \\
Raspberry & $31.35^{\mathrm{a}} \pm 0.62$ & $26.32^{\mathrm{a}} \pm 0.88$ & $8.59^{\mathrm{a}} \pm 0.76$ & $27.69^{\mathrm{a}} \pm 1.02$ & $17.89^{\mathrm{a}} \pm 1.13$ \\
Blackberry & $20.19^{\mathrm{c}} \pm 0.16$ & $1.35^{\mathrm{c}} \pm 0.15$ & $0.39^{\mathrm{c}} \pm 0.06$ & $1.41^{\mathrm{c}} \pm 0.15$ & $15.87^{\mathrm{a}} \pm 2.36$ \\
ANOVA & $p \leq 0.0001$ & $p \leq 0.0001$ & $p \leq 0.0001$ & $p \leq 0.0001$ & $p \leq 0.0203$ \\
\hline
\end{tabular}

Results are expressed as mean \pm standard deviation. Different letters indicate significant differences between mean values.

Table 3 shows the color parameters of fresh selected berry fruits. According to the Hunterlab [30], an $L^{*}$ value indicates the intensity of light or darkness. When the value of $L^{*}=0$, there is no reflection, indicating the presence of black, and when $L^{*}=100$, the reflection is greatest, indicating the presence of white. A value of $\mathrm{a}^{*}$ indicates the intensity of red or green, so negative values $\left(-\mathrm{a}^{*}\right)$ indicate the presence of green, and positive values $\left(+a^{*}\right)$ indicate the presence of red. A value of $b^{*}$ indicates the intensity of yellow or blue, so negative values $\left(-b^{*}\right)$ indicate the presence of blue and positive values $\left(+b^{*}\right)$ indicate the presence of yellow. The parameters $C$ and $h^{\circ}$ represent the color saturation, while the hue angle $\left(\mathrm{h}^{\circ}\right)$ indicates the color saturation. Based on the obtained results, the lowest $L^{*}$ value (20.19) was obtained for blackberry, as expected, since blackberry is specific for its dark blue/purple coloration among the other two berry species analyzed, while for raspberry (specific light red/pink coloration of fresh fruits), the obtained $\mathrm{L}^{*}$ value was the 
highest (31.35). Since tayberry is a hybrid between raspberry and blackberry, the obtained $\mathrm{L}^{*}$ value (23.2) is between the obtained $\mathrm{L}^{*}$ values of raspberry and blackberry, as expected. Also, the obtained $a^{*}$ and $b^{*}$ values for all the examined berry species in this study are consistent with their specific coloration of the fresh fruits. For example, higher $a^{*}$ and $b^{*}$ values were obtained for raspberry $(26.32 ; 8.59)$ and tayberry $(18.51 ; 4.01)$ as an indicator of more red color, while significantly lower $a^{*}$ values (1.35) were obtained for blackberry in conjunction with lower $b^{*}$ values $(0.39)$ as an indicator of more blue/purple color. All the obtained results of the analyzed chromaticity parameters are in agreement with other literature data $[25,28]$, indicating that the selected berry fruits in this study were at an appropriate stage of maturity and achieved specific fruit coloration for each berry species. It is important to note that external color intensity can often be correlated with specific pigments synthesized in the fruit [31-33].

The most valuable compounds from the nutritional content of berry fruits are specific phytochemicals that position berries among the fruits with the highest antioxidant activity. Berries contain a considerable amount of various biologically active compounds, mainly ascorbic acid and phenolics (anthocyanins, flavanols, flavonoids, phenolic acids, tannins), which either singly or in combination have various functional properties that are essential for human health $[2,5,34]$. It is important to mention that numerous scientific studies prove that genetic traits, together with biotic, abiotic, and anthropogenic factors, have a significant influence on the synthesis pathways of metabolism and the accumulation, and thus the final content of specialized metabolites in berry fruits [35-37]. According to other scientific studies, the AsA content in raspberries is in the range of about 15-60 mg/100 g fw [26-29], while in this study, higher values were found. Then, by comparing the results of AsA in tayberries, higher values were also obtained in this study compared to other literature data that indicate values of about 20-60 mg/100 g fw [26-28]. As for the value of AsA in blackberries, values of $15-35 \mathrm{mg} / 100 \mathrm{~g}$ fw were found in other literature citations $[26,27,29,37]$, while in this study significantly higher values were obtained, even about 2 times. The content of total phenolics (TPC), non-flavonoids (TNFC), and flavonoids (TFC) also differed greatly in the selected berry species (Table 4). The highest TPC value was determined in blackberry (512.93 mg GAE/100 $\mathrm{g} \mathrm{fw}$ ) and the lowest in raspberry (187.57 mg GAE/100 g fw). Due to the high TPC content, the values of TNFC and TFC are also relatively high; TNFC values range from $75.94 \mathrm{mg}$ GAE/100 $\mathrm{g}$ fw (raspberry) to $251.58 \mathrm{mg}$ GAE/100 $\mathrm{g}$ fw (blackberry), while TFC values range from $109.62 \mathrm{mg} \mathrm{GAE} / 100 \mathrm{~g} \mathrm{fw}$ (raspberry) to 261.34 mg GAE/100 $\mathrm{g}$ $\mathrm{fw}$ (blackberry). These results are also consistent with other literature data, which also state that the blackberry and tayberry generally have higher TPC values compared to raspberry [26-29,37]. According to other literature, TPC values in raspberry ranged from 200-700 mg GAE/100 g fw [26,28,29,37], in tayberry about $200 \mathrm{mg}$ GAE/100 g fw [26], while in blackberry in the range of $250-600 \mathrm{mg}$ GAE/100 $\mathrm{g} \mathrm{fw}[26,29,37]$. Genetic traits also had a significant effect on total anthocyanin content (TAC), as significant differences in TAC were observed among the berry species studied (Table 4). As expected, the highest TAC $(1557.18 \mathrm{mg} / \mathrm{kg})$ was determined in blackberry, being a species with characteristic dark blue/purple coloration, while the TAC value was as much as 2.5 times lower in tayberry (purple coloration) and as much as 7 times lower in raspberry (red/pink coloration). These results can be supported by other literature data, which also state that blackberries have higher TAC value compared to tayberries and especially raspberries [26-29,37]. Indeed, based on the obtained results of the content of phytochemicals in different berry species analyzed in the fresh state, it can be concluded that genetic characteristics have a significant influence on the content, but also comparing with other literature, it should be emphasized that besides genetic characteristics, pedoclimatic conditions during the cultivation of berry fruits also show a strong influence. 
Table 4. Content of bioactive substances in fresh berry fruits.

\begin{tabular}{|c|c|c|c|c|c|}
\hline Species & $\begin{array}{c}\text { AsA } \\
(\mathrm{mg} / 100 \mathrm{~g} \text { fw })\end{array}$ & $\begin{array}{c}\text { TPC } \\
(\mathrm{mg} \mathrm{GAE} / 100 \mathrm{~g} \mathrm{fw})\end{array}$ & $\begin{array}{c}\text { TNFC } \\
(\mathrm{mg} \mathrm{GAE} / 100 \mathrm{~g} \mathrm{fw})\end{array}$ & $\begin{array}{c}\text { TFC } \\
(\mathrm{mg} \mathrm{GAE} / 100 \mathrm{~g} \mathrm{fw})\end{array}$ & $\begin{array}{c}\text { TAC } \\
(\mathrm{mg} / \mathrm{kg})\end{array}$ \\
\hline Tayberry & $128.34^{b} \pm 3.64$ & $330.22^{b} \pm 0.29$ & $152.81^{b} \pm 0.59$ & $177.41^{b} \pm 0.57$ & $606.8^{b} \pm 4.26$ \\
\hline Raspberry & $70.94^{c} \pm 2.84$ & $185.57^{\mathrm{c}} \pm 0.46$ & $75.94^{\mathrm{c}} \pm 0.52$ & $109.62^{c} \pm 0.75$ & $221.61^{\mathrm{c}} \pm 1.94$ \\
\hline Blackberry & $142.46^{\mathrm{a}} \pm 2.49$ & $512.92^{\mathrm{a}} \pm 1.42$ & $251.58^{\mathrm{a}} \pm 1.03$ & $261.34^{\mathrm{a}} \pm 1.05$ & $1557.18^{\mathrm{a}} \pm 1.85$ \\
\hline ANOVA & $p \leq 0.0001$ & $p \leq 0.0001$ & $p \leq 0.0001$ & $p \leq 0.0001$ & $p \leq 0.0001$ \\
\hline
\end{tabular}

AsA—ascorbic acid content; TPC—-total phenol content; TNFC—-total non-flavonoid content; TFC—-total flavonoid content; TAC—-total anthocyanin content. Results are expressed as mean \pm standard deviation. Different letters indicate significant differences between mean values.

Based on the high determined content of phytochemicals, the determined values of antioxidant capacity of the selected berry species were also high (Figure 1). The contribution of individual phytochemicals to the antioxidant activity of individual berry fruit species has been investigated in some studies [28]. For example, Beekwiler et al. [38] reported a relatively low contribution of vitamin $C$ to the antioxidant activity in raspberries, about $20 \%$, while for anthocyanins, about $25 \%$ of the antioxidant capacity of red raspberry fruits was reported. Poiana et al. [17] and Viskelis et al. [28] found highly correlated antioxidant activity with total phenolics content. According to the obtained results, the analyzed berry species differ significantly in terms of antioxidant capacity, the highest being found for blackberry $(1764 \mu \mathrm{mol} \mathrm{TE} / \mathrm{kg})$ and the lowest for raspberry $(1742 \mu \mathrm{mol} \mathrm{TE} / \mathrm{L})$. These results were expected based on the determined content of phytochemicals, as blackberry stands out with the highest content of vitamin C, TPC (TNFC, TFC), and TAC.

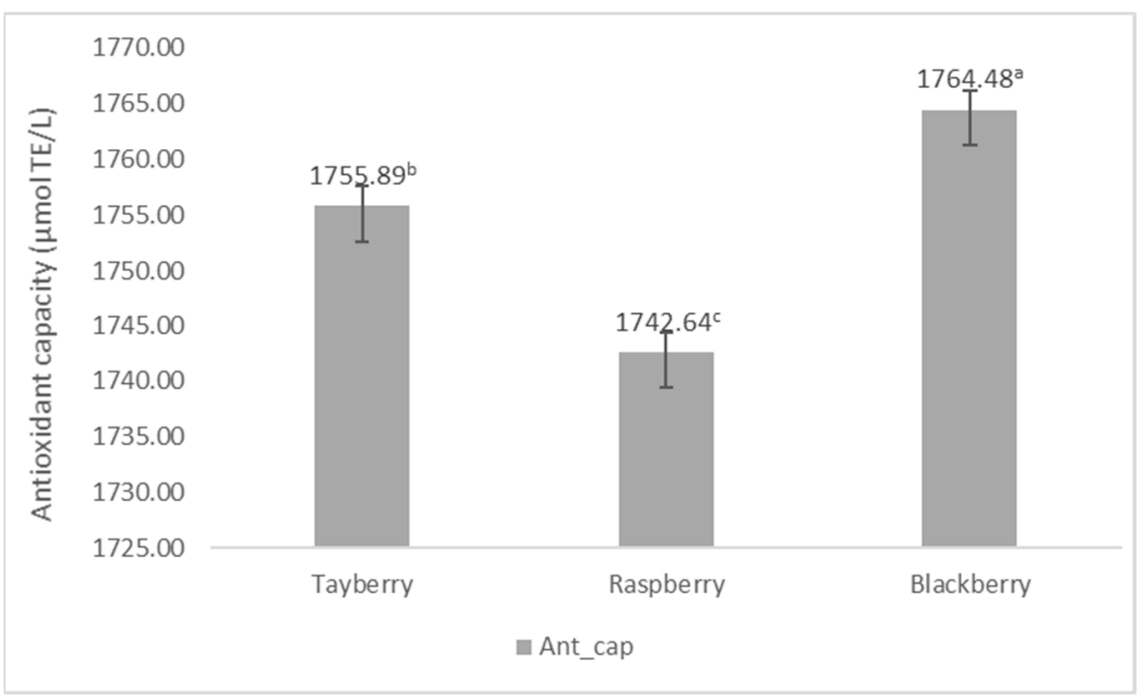

Figure 1. Antioxidant capacity ( $\mu \mathrm{mol} \mathrm{TE} / \mathrm{L}$ ) of berry fruit species in fresh state. Ant_cap-antioxidant capacity. Different letters indicate significant differences between mean values at $p \leq 0.0001$.

\subsection{Drip Loss of Frozen Berry Fruits}

One of the greatest disadvantages of the freezing process, generally for all fruits and vegetables, but especially for soft fruits (because of their high-water content), is thawing, or the loss of fruit juice during thawing (drip loss). Thawed fruit inevitably changes texture-the tissue becomes softer, which is ultimately also an undesirable characteristic for the consumer. The change in texture and, above all, the greater loss of cell juice is more pronounced when using classical methods of freezing (temperatures around $-18{ }^{\circ} \mathrm{C}$ and duration $24 \mathrm{~h}$ ) mainly because such conditions mean slower freezing rate, during which larger ice crystals form in the cell tissue, causing considerable damage to cells and tissue. Upon thawing, these large crystals result in a higher release of water, which, as mentioned earlier, results in undesirable changes in the texture of the product. In contrast, 
quick freezing at lower freezing temperatures (approximately -30 to $-150{ }^{\circ} \mathrm{C}$ ) and much shorter time (approximately $30 \mathrm{~min}$ or shorter) results in the formation of a larger number of small ice crystals and thus fewer changes in tissue texture, which is considered one of the most valuable advantages of the quick-freezing process [15]. In this study, we monitor the drip loss, cell sap loss, during thawing of different berry species with respect to the freezing method, and during storage of three months (Figure 2). Comparing the berry species regardless of the freezing method, blackberry shows the lowest average drip loss during thawing (average 1.84\%), while tayberry shows the highest $(3.44 \%)$. These results are expected due to the characteristic morphological fruit structure of each berry species; blackberry fruits are characterized by a higher, more pronounced fruit firmness, while raspberry and tayberry have a much lower fruit firmness (softer tissue) and a thinner fruit skin. If we consider the freezing method, regardless of the berry species, significantly higher values of drip loss are obtained with classic freezing, on average $4.08 \%$, which even means a four-fold higher loss compared to quick-freezing (on average $0.95 \%$ ). It is also important to emphasize that water loss significantly affects the thawing process itself. It should be noted that when the thawing rate is higher, the water loss from the fruit is less pronounced [14]. And since classically frozen fruit typically takes about $24 \mathrm{~h}$ to thaw, while quick frozen fruit takes about $30 \mathrm{~min}$, it is expected that water loss will be significantly less in quick frozen fruit. During the three-month storage period (Figure 2), a slightly lower drip loss was observed, but again significant differences were found in relation to the freezing method, with significant drip loss observed in classically frozen fruits, on average $1.54 \%$, irrespective of berry species, while in quick frozen fruits, this loss was slightly lower, on average $1.1 \%$. Also, significant differences of drip loss during storage were observed depending on the berry species, but now during storage, a higher drip loss was observed for blackberry fruit, on average $1.63 \%$, while the lowest was observed for tayberry fruit (on average $1 \%)$.

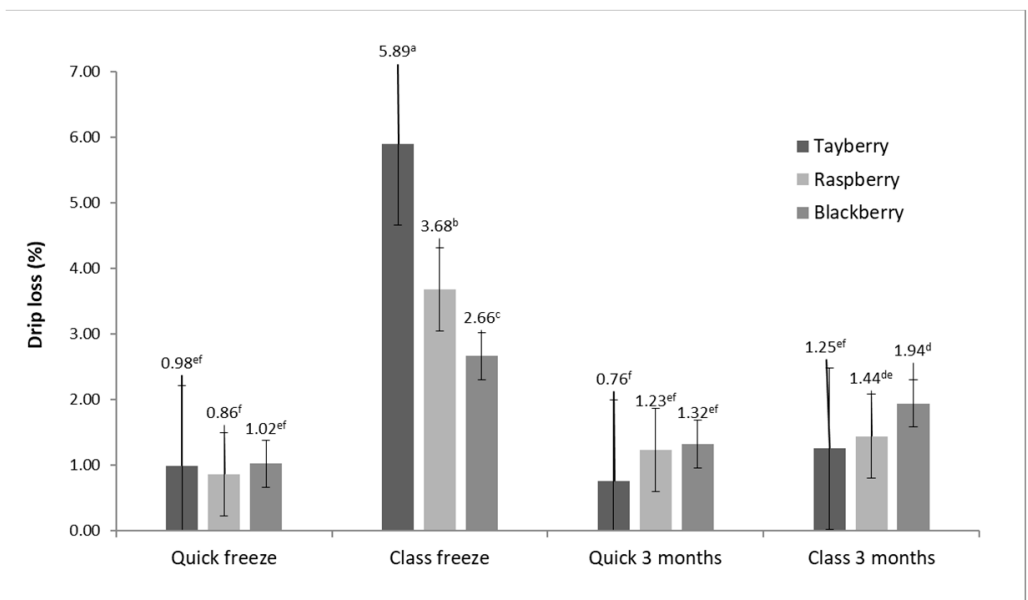

Figure 2. Drip loss of frozen berry fruits and after storage as a function of freezing method. Different letters indicate significant differences between mean values at $p \leq 0.0001$. Significance of interaction: $\mathrm{V} \times \mathrm{F}$ - variety and freezing method $p \leq 0.2789 ; \mathrm{V} \times \mathrm{S}$ - variety and storage $p \leq 0.1531 ; \mathrm{F} \times \mathrm{S}-$ freezing method and storage $p \leq 0.0001 ; \mathrm{V} \times \mathrm{F} \times \mathrm{S}$ - variety, freezing method and storage $p \leq$ 0.0001 .

\subsection{Physico-Chemical Properties of Frozen Berry Fruits}

One of the major challenges of the freezing process is the control and regulation of ice crystal growth, as the crystallization process causes structural changes, potential tissue damage, but also changes in nutrient composition and degradation of valuable bioactive compounds. It is for these reasons that the right choice of freezing method can successfully influence the quality of the final product. Many studies prove the advantages of using modern freezing methods (use of cryogenics, IQF method, etc.) in preserving the quality of 
the final product $[1,8,9,17,39]$. However, above all, it is important to optimize the choice of the method itself, i.e., to adapt it to the type of fruit and the properties and conditions that significantly affect the preservation of each nutrient. Some phytochemicals show higher resistance, stability to certain processing conditions, such as temperature conditions, process duration, influence of the acidity of the medium, oxygen or light, etc.

The analyzed physico-chemical properties of frozen berry fruits are presented in Table 5. Significant differences of physico-chemical parameters were determined between all berry fruits depending on the freezing method (classical freezing, quick freezing) and storage. Total dry matter content (DM) values, regardless of berry fruit type, were generally higher in fruits that were classically frozen, with an average value of $16.44 \%$ compared to the quick-frozen fruits, where the average DM value was $15.38 \%$. Thus, the water content in classically frozen fruits was slightly lower (average $84 \%$ ) than in the quick-frozen fruits (average 85\%), which is to be expected based on the obtained results of drip loss. Indeed, the drip loss was more pronounced in classically frozen berry fruits compared to the quickfrozen ones, so it can be concluded that the application of the quick-freezing process does not significantly affect the loss of water or cell sap during thawing. A slightly lower DM value (average $16.25 \%$ ) was determined after 3 months of storage, but compared to DM after classical freezing, this is a reduction of about $1 \%$, which is negligible and also depending on the statistical analysis, not significant. On the contrary, during the three-month storage period of quick-frozen berry fruits, regardless of the species, a slightly higher average DM value was observed, compared to the samples which were not stored; however, this increase is negligible (around $0.5 \%$ ). On comparing the DM values in fruits after a three-month storage period depending on the freezing method, it is observed that slightly higher DM values (on average $16.25 \%$ ) were determined in classically frozen berries, about $5 \%$ higher, which is in agreement with the obtained drip loss results. Therefore, after a three-months storage period, berries frozen by quick-freeze method generally had higher water content (on average $84.57 \%$ ) compared to the classically frozen and stored fruits, which had on average $83.75 \%$ water content. These results are to be expected since we discussed above how the application of quick-freezing in fruits does not lead to such significant fractures and degradation of cell structures due to the formation of ice crystals, thus there was no significant water loss from the fruits during thawing. In conclusion, it can be stated that berry fruits frozen by the quick-freezing method do not show such a pronounced loss of water after three months of storage as fruits frozen by the classical method.

Total soluble solids content (TSS) was generally higher in berry fruits classically frozen - the average determined value, regardless of the berry species, was $11.93 \%$, which is compared to the quick-frozen fruits: about $10 \%$ higher content. Depending on the berry species, a slight decrease in TSS was observed by quick-freezing in all the berries studied. During storage, a further slight downward trend for TSS content was observed in the classically frozen fruits (on average a decrease of $4 \%$ ), but this trend was opposite in the quick-frozen fruits, namely a slight increase of TSS during storage of the quickfrozen fruits was observed. Sugars act as natural cryoprotectors (colligative type), thus reducing drip loss, preserving the original color and flavor of the fruit, and allowing higher retention of bioactive compounds in the plant material. The main cryoprotectants mechanism of sugars is based on the reduction of free water activity in cells, leading to a lowering of the freezing point; however, depending on their molecular weight, different sugar molecules also influence the ice formation process by modulating ice crystal growth Monosaccharides, which are dominantly present in berry fruits, significantly lower the freezing point, allowing a significant amount of unfrozen water to remain even at very low temperatures $[9,40]$. Based on the above, it is expected that quick-frozen berry fruits generally have a lower total soluble solids content compared to classically frozen fruits. The organic acids of fruits are relatively stable compounds in relation to the freezing process, and in general their content is considerably preserved at lower temperatures. A slight decrease in the content of organic acids is often marked in long-term storage, as in the case of the TSS content, which generally depends on the rate of respiration of the fruit. But in 
general, the respiration rate is significantly inhibited during storage at low temperatures, which allows the preservation of TSS and total organic acids [41,42].

Table 5. Physicochemical properties of frozen berry fruits.

\begin{tabular}{ccccc}
\hline Species & DM (\%) & TSS (\%) & TA (\%) & pH \\
\hline & & Classical freezing & \\
Tay-CLAS & $15.37^{\mathrm{de}} \pm 0.12$ & $11.50^{\mathrm{b}} \pm 0.1$ & $1.39^{\mathrm{h}} \pm 0.01$ & $3.19^{\mathrm{b}} \pm 0.02$ \\
Rsp-CLAS & $17.61^{\mathrm{a}} \pm 0.27$ & $12.53^{\mathrm{a}} \pm 0.06$ & $1.86^{\mathrm{d}} \pm 0.02$ & $2.96^{\mathrm{ef}} \pm 0.01$ \\
Blc-CLAS & $16.33^{\mathrm{c}} \pm 0.18$ & $11.77^{\mathrm{b}} \pm 0.15$ & $1.16^{\mathrm{j}} \pm 0.05$ & $3.08 \mathrm{c} \pm 0.01$ \\
& & 3 months storage & & \\
Tay-CLAS & $15.74^{\mathrm{d}} \pm 0.18$ & $10.93^{\mathrm{cde}} \pm 0.06$ & $1.63^{\mathrm{e}} \pm 0.02$ & $3.22^{\mathrm{a}} \pm 0.02$ \\
Rsp-CLAS & $17.59^{\mathrm{a}} \pm 0.21$ & $11.77^{\mathrm{b}} \pm 0.23$ & $2.20^{\mathrm{b}} \pm 0.01$ & $2.94^{\mathrm{fg}} \pm 0.01$ \\
Blc-CLAS & $15.42^{\mathrm{de}} \pm 0.27$ & $11.67^{\mathrm{b}} \pm 0.06$ & $1.27^{\mathrm{i}} \pm 0.01$ & $3.05^{\mathrm{d}} \pm 0.02$ \\
& & Quick-freezing & & \\
Tay-QF & $13.92^{\mathrm{g}} \pm 0.24$ & $10.50^{\mathrm{e}} \pm 0.61$ & $1.43^{\mathrm{g}} \pm 0.02$ & $3.21^{\mathrm{a}} \pm 0.02$ \\
Rsp-QF & $16.79^{\mathrm{b}} \pm 0.27$ & $11.32^{\mathrm{bc}} \pm 0.5$ & $2.02^{\mathrm{c}} \pm 0.03$ & $2.97^{\mathrm{e}}$ \\
Blc-QF & $15.41^{\mathrm{de}} \pm 0.16$ & $10.73^{\mathrm{de}} \pm 0.64$ & $1.07^{\mathrm{k}}$ & $3.21^{\mathrm{a}} \pm 0.02$ \\
& & 3 months storage & & \\
Tay-QF & $14.43^{\mathrm{f}} \pm 0.33$ & $11^{\mathrm{cd}}$ & $1.58^{\mathrm{f}} \pm 0.03$ & $3.17^{\mathrm{b}} \pm 0.01$ \\
Rsp-QF & $16.65^{\mathrm{bc}} \pm 0.24$ & $12.60^{\mathrm{a}} \pm 0.1$ & $2.28^{\mathrm{a}} \pm 0.01$ & $2.93^{\mathrm{g}} \pm 0.01$ \\
Blc-QF & $15.23^{\mathrm{e}} \pm 0.14$ & $11.53^{\mathrm{b}} \pm 0.12$ & $1.26^{\mathrm{i}} \pm 0.01$ & $3.19^{\mathrm{b}} \pm 0.01$ \\
ANOVA & $p \leq 0.0001$ & $p \leq 0.0405$ & $p \leq 0.0001$ & $p \leq 0.0001$ \\
V $\times$ F & 0.0152 & 0.6167 & 0.2555 & 0.0001 \\
V $\times$ S & 0.1545 & 0.6690 & 0.0024 & 0.7868 \\
F $\times$ S & 0.7334 & 0.0014 & 0.9255 & 0.7381 \\
V $\times$ F $\times$ S & 0.0001 & 0.0001 & 0.0001 & 0.0001 \\
\hline
\end{tabular}

DM-dry matter content; TSS—-total soluble solids; TA-total acid content; $\mathrm{V} \times \mathrm{F}$-interaction of variety and freezing method; $\mathrm{V} \times \mathrm{S}$-interaction between variety and storage; $\mathrm{F} \times \mathrm{S}$-interaction of freezing method and storage; $\mathrm{V} \times \mathrm{F} \times \mathrm{S}$-interaction of variety, freezing method and storage. Results are expressed as mean \pm standard deviation. Different letters indicate significant differences between mean values.

The total titratable acidity content (TA) of frozen berry fruits analyzed in this study is shown in Table 5. Significant differences were found, depending on both the freezing method, berry species, and storage. In general, TA was slightly lower (about $3 \%$ on average) in classically frozen berry fruits, regardless of berry species, compared to the quick-frozen fruits. But during the three-month storage period, there are significant changes in TA content, while the same increasing trend was observed for both classically and frozen fruits. Therefore, after the three-month storage period of classically frozen berry fruits, the TA content increased by $16 \%$ on average, while the TA content increased by about $13 \%$ for the quick-frozen fruits. This recorded increase in total organic acid content during storage differs from the data available in other studies, and a possible reason for this trend in this study may be a significant reduction in the respiration rate of fruits when processed and stored at lower temperatures, because the lower the storage temperature, the slower the respiration rate, which negatively affects the content of soluble substances, such as sugars or organic acids. For classically frozen berry fruits, the average $\mathrm{pH}$ was 3.08, while for quick-frozen, the average $\mathrm{pH}$ was 3.13 , regardless of berry species (Table 5). During storage, a slight variation in $\mathrm{pH}$ was observed in both classic and quick-frozen fruits. The $\mathrm{pH}$ has a direct influence on fruit color, especially in berry fruits, as the anthocyanin content (and thus fruit coloration) is strongly influenced by $\mathrm{pH}$ of media. In addition, some studies have noted the high correlation between $\mathrm{pH}$ and color quality and calculated that berries should have a $\mathrm{pH}$ of 3.51 or lower to have acceptable color after freezing [43].

Color is one of the four main characteristics representing the quality of the final product, and it is one of the most valuable morphological parameters from a consumer's point of view. Fruit color is strongly influenced, not only by agrotechnical measures and agronomic factors during cultivation, but also by the different postharvest technological processes, such as pre-cooling, packaging, freezing, etc. [8]. The selection of an appropriate 
method of berry processing is extremely challenging, mainly because of the characteristic soft fruit texture of these fruit species, each processing segment inevitably affects the final fruit quality, especially the color. Methods involving minimal processing and rapid freezing are one of the most desirable to preserve the original color of the fruit after freezing. Depending on the results of chromaticity parameters of different berry species studied in this research (Table 6), both the freezing method and the storage period have a significant $(p \leq 0.0001)$ influence on fruit color. Significant changes in all analyzed color parameters were also observed between the fresh (Table 5) and frozen berry fruits studied. Namely, regardless of the freezing method, lower $L^{*}$ values and higher $a^{*}$ and $b^{*}$ values were observed in frozen berry fruits, indicating a change in the characteristic berry color during the freezing process. In general, the fruits were darker after freezing and had a more pronounced red or blue coloration, depending on the species studied. Comparing the influence of freezing method (classical and quick-freezing) on fruit lightness/darkness $\left(\mathrm{L}^{*}\right)$ of all studied berry species, it can be observed that $L^{*}$ values were lower after quickfreezing, indicating a darker fruit color; while $\mathrm{a}^{*}$ values (red coloration) did not differ significantly in tayberries and raspberries as a function of freezing method, except for blackberry, for which lower $\mathrm{a}^{*}$ values were observed in quick-freezing compared to classical freezing, indicating the lower presence of red coloration expected due to the specific dark blue/purple coloration of the fruits. The values of the chromaticity parameter $\mathrm{b}^{*}$, indicating the presence of yellow $\left(+b^{*}\right)$ and blue $\left(-b^{*}\right)$ color, did not change significantly as a function of freezing method; a slight variation was observed in tayberry fruits for which a slightly lower $b^{*}$ value was obtained after quick-freezing, indicating a greater presence of blue coloration. As expected, the storage period of three months also affected the color change of all berry species studied, but these differences were not so significant for both classically and quick-frozen fruits. In general, based on all color parameters analyzed, the color of quick-frozen berry fruits was slightly better preserved during storage for each specific berry species. However, since fruit color is directly related to the presence of specific pigments, in this case anthocyanins, the influence of freezing method and storage period on pigment compounds will be further clarified in the chapter on bioactive compound content.

Table 6. Chromatic parameters of frozen berry fruits.

\begin{tabular}{|c|c|c|c|c|c|}
\hline Species & $L^{*}$ & $a^{*}$ & $\mathbf{b}^{*}$ & $\mathrm{C}$ & $\mathbf{h}^{\circ}$ \\
\hline \multicolumn{6}{|c|}{ Classical freezing } \\
\hline Tay-CLAS & $21.38^{\mathrm{dc}} \pm 0.96$ & $23.37^{b} \pm 0.79$ & $5.14^{\mathrm{cd}} \pm 0.74$ & $23.97^{\mathrm{c}} \pm 0.85$ & $12.10^{\mathrm{cd}} \pm 1.69$ \\
\hline Rsp-CLAS & $28.93^{b} \pm 2.62$ & $30.84^{\mathrm{a}} \pm 0.73$ & $11.26^{\mathrm{a}} \pm 0.29$ & $32.96^{\mathrm{ab}} \pm 0.45$ & $19.98^{a} \pm 0.77$ \\
\hline Blc-CLAS & $19.59^{\text {def }} \pm 0.59$ & $10.24^{c} \pm 0.82$ & $2.11^{\mathrm{e}} \pm 0.19$ & $10.46^{\mathrm{d}} \pm 0.85$ & $11.98^{\mathrm{cd}} \pm 0.14$ \\
\hline \multicolumn{6}{|c|}{3 months storage } \\
\hline Tay-CLAS & $20.96^{\text {cde }} \pm 1.14$ & $23.41^{\mathrm{b}} \pm 1.49$ & $4.89^{\mathrm{c}} \pm 0.99$ & $23.94^{\mathrm{c}} \pm 1.66$ & $11.59^{\text {cde }} \pm 1.63$ \\
\hline Rsp-CLAS & $35.93^{\mathrm{a}} \pm 1.11$ & $31.14^{\mathrm{a}} \pm 0.47$ & $9.17^{b} \pm 0.56$ & $32.47^{\mathrm{ab}} \pm 0.60$ & $16.39^{b} \pm 0.72$ \\
\hline Blc-CLAS & $18.65^{\mathrm{f}} \pm 0.55$ & $7.46^{\mathrm{d}} \pm 2.27$ & $1.49^{\mathrm{e}} \pm 0.41$ & $7.62^{\mathrm{e}} \pm 2.30$ & $11.53^{\text {cde }} \pm 2.58$ \\
\hline \multicolumn{6}{|c|}{ Quick freezing } \\
\hline Tay-QF & $19.83^{\text {def }} \pm 0.86$ & $24.02^{b} \pm 1.23$ & $4.83^{\mathrm{d}} \pm 0.31$ & $24.51^{\mathrm{c}} \pm 1.26$ & $11.32^{\text {cde }} \pm 0.17$ \\
\hline Rsp-QF & $28.73^{b} \pm 2.93$ & $31.30^{\mathrm{a}} \pm 1.04$ & $11.69^{\mathrm{a}} \pm 1.10$ & $33.39^{\mathrm{a}} \pm 1.35$ & $20.35^{\mathrm{a}} \pm 1.25$ \\
\hline Blc-QF & $18.76^{\text {ef }} \pm 0.33$ & $8.40^{\mathrm{cd}} \pm 1.05$ & $1.41^{\mathrm{e}} \pm 0.19$ & $8.52^{\mathrm{de}} \pm 1.07$ & $9.53^{\mathrm{e}} \pm 0.33$ \\
\hline \multicolumn{6}{|c|}{3 months storage } \\
\hline Tay-QF & $22.19^{\mathrm{c}} \pm 1.11$ & $24.62^{b} \pm 0.99$ & $6.02^{\mathrm{c}} \pm 0.79$ & $25.38^{\mathrm{c}} \pm 1.18$ & $13.45^{\mathrm{c}} \pm 1.10$ \\
\hline Rsp-QF & $35.04^{\mathrm{a}} \pm 1.23$ & $29.72^{\mathrm{a}} \pm 1.26$ & $8.50^{b} \pm 0.73$ & $30.88^{b} \pm 1.36$ & $15.90^{\mathrm{b}} \pm 0.68$ \\
\hline Blc-QF & $18.61^{\mathrm{f}} \pm 0.15$ & $10.06^{\mathrm{c}} \pm 1.21$ & $2.01^{\mathrm{e}} \pm 0.19$ & $10.27^{\mathrm{d}} \pm 1.22$ & $11.17^{\mathrm{de}} \pm 1.63$ \\
\hline ANOVA & $p \leq 0.0001$ & $p \leq 0.0001$ & $p \leq 0.0001$ & $p \leq 0.0001$ & $p \leq 0.0001$ \\
\hline $\mathrm{V} \times \mathrm{F}$ & 0.9825 & 0.4378 & 0.8020 & 0.4361 & 0.4231 \\
\hline $\mathrm{V} \times \mathrm{S}$ & 0.0001 & 0.6267 & 0.0001 & 0.2721 & 0.0001 \\
\hline $\mathrm{F} \times \mathrm{S}$ & 0.8293 & 0.8752 & 0.8428 & 0.8692 & 0.6143 \\
\hline $\mathrm{V} \times \mathrm{F} \times \mathrm{S}$ & 0.0002 & 0.0536 & 0.0001 & 0.0345 & 0.0011 \\
\hline
\end{tabular}

$\mathrm{V} \times \mathrm{F}$-interaction of variety and freezing method; $\mathrm{V} \times \mathrm{S}$-interaction between variety and storage; $\mathrm{F} \times \mathrm{S}$-interaction of freezing method and storage; $\mathrm{V} \times \mathrm{F} \times \mathrm{S}$-interaction of variety, freezing method and storage. Results are expressed as mean \pm standard deviation. Different letters indicate significant differences between mean values. 


\subsection{Bioactive Compounds Content and Antioxidant Capacity of Frozen Berry Fruits}

The results of the content of bioactive compounds in frozen fruits of different berry species are presented in Table 7 . According to the obtained results, all analyzed bioactive compounds differ significantly $(p \leq 0.0001)$ according to the freezing method and storage period. In general, regardless of the berry species, values of AsA content were significantly higher in quick-frozen samples, compared to the classically frozen ones, with the mentioned increase being particularly pronounced in the quick-freezing of blackberries, where the AsA content was preserved to even $56 \%$. It should be noted that the average AsA content in quick-frozen berry fruits, regardless of species, was as much as $28 \%$ higher, compared to the classically frozen fruits. Comparing the AsA content in frozen berry fruits, regardless of the freezing method, with the samples in fresh condition, a significant decrease in AsA content was observed, suggesting that freezing as a processing method also has a negative influence on AsA content. However, it should be emphasized that the mentioned decrease in AsA content was more pronounced in the classical freezing method, while by the quickfrozen method, the preservation of AsA content was more significant. As expected, the AsA content continued to decrease during the three-month storage period, regardless of the freezing method, but it should be noted that, in general, all berry species studied that were quick-frozen had higher AsA content after the storage period, on average about 13\% higher, compared to the AsA content in classically frozen fruit. When comparing the effect of storage time in both classically and frozen fruits, it should also be noted that the decrease in AsA content was more pronounced in quick-frozen fruits; in general, these samples even had a 13\% higher loss of AsA content during storage, compared to the classically frozen samples where only a small loss of AsA content was recorded during storage (less than $1 \%)$. The possible reason for such a variation in the loss of AsA content during storage of differently frozen berry species could be due to the storage conditions, as both the classically and frozen samples were stored at the same temperature $\left(-18^{\circ} \mathrm{C}\right)$, which initially caused further formation and growth of larger crystals; respectively, recrystallization, which often occurs when the frozen product is subjected to large temperature fluctuations, and this affects the number, size, shape, and position of the ice crystals previously formed during freezing [44]. From the obtained results, it can be concluded that the use of the freezing system can significantly affect the total content of AsA, mainly affecting its degradation in the fruits of different berry species. According to other literature data, the degradation, i.e., the reduction in AsA content, is a necessary consequence of the freezing process and the storage period, regardless of the applied system, i.e., the freezing and cold storage conditions, temperature, and time $[9,44]$. Some of the authors state that the degradation of AsA after freezing could be associated with drip losses without involving the degradation of the compound itself, since water can act as a carrier agent [14]. In addition, most authors emphasize that the use of freezing methods that require faster freezing rates, such as quickfreezing methods, i.e., lower temperatures and shorter freezing times, can significantly contribute to the preservation of AsA content in berry fruits, compared to the classical slower freezing methods (temperatures around $-20^{\circ} \mathrm{C}, 24 \mathrm{~h}$ ) $[9,14,45-47]$. 
Table 7. Content of bioactive substances in frozen berry fruits.

\begin{tabular}{|c|c|c|c|c|c|}
\hline Species & $\begin{array}{c}\text { AsA } \\
(\mathrm{mg} / 100 \mathrm{~g} \mathrm{dw})\end{array}$ & $\begin{array}{c}\text { TPC } \\
(\mathrm{mg} \mathrm{GAE} / 100 \mathrm{~g} \mathrm{dw})\end{array}$ & $\begin{array}{c}\text { TNFC } \\
\text { (mg GAE/100 g dw) }\end{array}$ & $\begin{array}{c}\text { TFC } \\
(\mathrm{mg} \mathrm{CTH} / 100 \mathrm{~g} \mathrm{dw})\end{array}$ & $\begin{array}{c}\text { TAC } \\
(\mathrm{mg} / \mathrm{kg} \mathrm{dw})\end{array}$ \\
\hline \multicolumn{6}{|c|}{ Classical freezing } \\
\hline Tay-CLAS & $649.96^{\mathrm{c}} \pm 4.64$ & $2275.26^{g} \pm 2.69$ & $1238.13^{\mathrm{d}} \pm 1.94$ & $1037.38^{\mathrm{d}} \pm 9.41$ & $771.42^{\mathrm{d}}$ \\
\hline Rsp-CLAS & $623.32^{\mathrm{C}} \pm 2.84$ & $1476.62^{\mathrm{j}} \pm 2.24$ & $844.67^{\mathrm{e}} \pm 1.38$ & $631.95^{\mathrm{e}} \pm 1.23$ & $372.49^{f}$ \\
\hline Blc-CLAS & $614.77^{\mathrm{c}} \pm 7.34$ & $3137.41^{b} \pm 2.75$ & $1691.99^{\mathrm{a}} \pm 1.25$ & $1445.42^{b} \pm 2.76$ & $1537.30^{\mathrm{a}}$ \\
\hline \multicolumn{6}{|c|}{ 3-month storage } \\
\hline Tay-CLAS & $649.43^{c} \pm 4.86$ & $2013.15^{\mathrm{h}} \pm 7.37$ & $1505.19^{\mathrm{b}} \pm 1.7$ & $507.95^{g} \pm 2.82$ & $727.75^{\mathrm{d}} \pm 4.78$ \\
\hline Rsp-CLAS & $607.89^{c} \pm 1.98$ & $1804.86^{\mathrm{i}} \pm 2.31$ & $687.11 \mathrm{~g} \pm 1.37$ & $1117.75^{\mathrm{cd}} \pm 1.14$ & $308.32^{f}$ \\
\hline Blc-CLAS & $621.68^{\mathrm{c}} \pm 2.04$ & $2630.23^{\mathrm{e}} \pm 3.67$ & $1386.65^{\mathrm{c}} \pm 4.46$ & $1243.57^{\mathrm{c}} \pm 1.47$ & $1420.45^{\mathrm{d}}$ \\
\hline \multicolumn{6}{|c|}{ Quick freezing } \\
\hline Tay-QF & $717.73^{b} \pm 3.27$ & $2469.45^{\mathrm{f}} \pm 1.05$ & $1267.38^{\mathrm{d}} \pm 3.06$ & $1202.08^{c} \pm 2.65$ & $839.89^{c} \pm 2.84$ \\
\hline Rsp-QF & $733.52^{b} \pm 2.29$ & $1501.55^{\mathrm{j}} \pm 1.88$ & $862.39 \mathrm{e} \pm 1.29$ & $639.16^{\mathrm{e}} \pm 2.51$ & $511.27^{\mathrm{e}}$ \\
\hline Blc-QF & $956.08^{\mathrm{a}} \pm 3.31$ & $3262.21^{\mathrm{a}} \pm 6.69$ & $1712.01^{\mathrm{a}} \pm 3.37$ & $1550.21^{\mathrm{a}} \pm 2.76$ & $1560.87^{\mathrm{a}}$ \\
\hline \multicolumn{6}{|c|}{ 3-month storage } \\
\hline Tay-QF & $781.28^{a} \pm 5.25$ & $2991.35^{c} \pm 6.76$ & $1523.40^{b} \pm 3.62$ & $1467.32^{\mathrm{ab}} \pm 3.05$ & $820.11^{\mathrm{d}} \pm 1.55$ \\
\hline Rsp-QF & $745.29^{b} \pm 2.81$ & $1861.57^{\mathrm{i}} \pm 2.75$ & $741.36^{\mathrm{f}} \pm 1.48$ & $1120.21^{\mathrm{cd}} \pm 1.38$ & $348.71^{\mathrm{f}}$ \\
\hline Blc-QF & $598.24^{\mathrm{c}} \pm 3.13$ & $2826.55^{\mathrm{d}} \pm 4.03$ & $1407.05^{\mathrm{c}} \pm 1.27$ & $1419.5^{\mathrm{ab}} \pm 1.52$ & $1464.11^{\mathrm{b}}$ \\
\hline ANOVA & $p \leq 0.0001$ & $p \leq 0.0405$ & $p \leq 0.0001$ & $p \leq 0.0001$ & $p \leq 0.0001$ \\
\hline $\mathrm{V} \times \mathrm{F}$ & 0.7220 & 0.0109 & 0.8691 & 0.0005 & 0.2787 \\
\hline $\mathrm{V} \times \mathrm{S}$ & 0.0369 & 0.2170 & 0.0001 & 0.2398 & 0.2355 \\
\hline $\mathrm{F} \times \mathrm{S}$ & 0.1008 & 0.6887 & 0.9835 & 0.3109 & 0.7623 \\
\hline $\mathrm{V} \times \mathrm{F} \times \mathrm{S}$ & 0.0001 & 0.0001 & 0.0001 & 0.0001 & 0.0022 \\
\hline
\end{tabular}

$\mathrm{V} \times \mathrm{F}$-interaction of variety and freezing method; $\mathrm{V} \times \mathrm{S}$-interaction between variety and storage; $\mathrm{F} \times \mathrm{S}$-interaction of freezing method and storage; $\mathrm{V} \times \mathrm{F} \times \mathrm{S}$-interaction of variety, freezing method and storage. Results are expressed as mean \pm standard deviation. Different letters indicate significant differences between mean values.

Polyphenolic compounds are relatively not so prone to degradation by freezing process [48-50] and some authors even reported an increase in the phenolic compounds content after freezing $[8,51]$. Similar to those reported data, the results obtained in this study also indicate the increase in total phenol content (TPC) after freezing. Significant differences in all analyzed polyphenolic compounds were determined considering the freezing method (Table 7); in quick-frozen berry fruits, regardless of the species, on average $5 \%$ higher TPC content, 2\% higher TNFC content, and 9\% TFC content were recorded compared to the classically frozen berries. In general, the highest TPC, TNFC, and TFC values, both in quick-frozen and classically frozen samples, were determined in blackberry. Quick-freezing method most affected the preservation of TPC in tayberry species; approximately $9 \%$ higher TPC was recorded in quick-frozen samples, compared to the classically frozen ones. The storage period expectedly led to a further reduction in the content of total polyphenolic compounds, both in quick and classically frozen samples. After three-month storage in classically frozen berry fruits, regardless of the species, TPC content decreased about $7 \%$, TNFC about $6 \%$, and TFC content about $9 \%$. During the storage of quick-frozen berries, some deviation in TPC content was recorded in tayberry and raspberry samples, wherein after storage, somewhat higher TPC values were determined. In blackberry, the same declining trend of TPC content in the storage period was recorded, both in quick and classically frozen fruits; in classically frozen blackberries about 19\% lower TPC content was determined after three-month storage, while in quick-frozen, about 15\% lower TPC was recorded after the storage period. One of the most characteristic compounds from the group of polyphenolics for the berry fruits are anthocyanins. As expected, the freezing method significantly affected $(p \leq 0.0001)$ total anthocyanin content (TAC) of analyzed berry species (Table 7). In general, regardless of the berry species, the quick-freezing process contributed to better preservation of TAC. For instance, in quick-frozen blackberry fruits, about $2 \%$ higher TAC was recorded compared to the classical freezing, in tayberry fruits about $9 \%$ higher, and in raspberry even 37\% higher TAC was determined. During the storage, further decrease of TAC was recorded in all analyzed berry species. 
Approximately $10 \%$ loss of TAC was recorded both during storage of classically frozen and quick-frozen berries. The most pronounced loss of TAC during storage of classically frozen berry species-21\%-was recorded for raspberries. Also, for the same species, a more pronounced loss (46\%) of TAC was recorded during the storage of quick-frozen fruits. On comparing the TAC content of frozen berry fruits, it can be concluded that significant loss of TAC was recorded during freezing, with the exception of blackberry in which even higher TAC values were recorded specifically after quick-freezing. Structural tissue changes as well as disruption of cell integrity are a direct consequence of ice crystal formation during the freezing process, causing, among other things, further chemical and enzymatic changes leading to temporal reduction or loss of certain plant pigments (e.g., conversion of chlorophyll to phaeophytin), then browning of components due to enzymatic and oxidative reactions, and finally frequent loss of polyphenol and anthocyanin content $[45,52]$. Another possible cause for the degradation of polyphenolic compounds, especially anthocyanins, is the occurrence of leaching during the thawing process, where the compounds are more exposed to oxygen during the thawing phase and oxidation processes occur much faster [53]. It is also interesting to note that some studies (in addition to ours for some berry species) have found higher levels of polyphenols and anthocyanins after the freezing process. Indeed, an increase in content after freezing may lead to the release of binding phenolic compounds and anthocyanins [54,55].

As mentioned above, some authors reported an increase in the content of bioactive compounds (especially phenols and anthocyanins) after the freezing process, leading to an increase in antioxidant activity and consequently to an increase in the overall nutritional quality of the final product $[8,10,51]$. Freezing is recognized as a technology for the production of high-quality foods, as it has been shown to have very little effect on the reduction of bioactive compounds and consequently on the antioxidant properties of a product [9]. According to the results presented in Figure 3, the highest antioxidant capacity was recorded for blackberries in both quick-frozen and classically frozen berry fruits (quick-frozen $1911.07 \mu \mathrm{mol} \mathrm{TE} / \mathrm{L}$; classically frozen $1842.84 \mu \mathrm{mol} \mathrm{TE} / \mathrm{L}$ ). Both values are significantly higher than those recorded for blackberry in the fresh state (data from Figure 1). The greatest decrease in antioxidant capacity during freezing in general (regardless of the method) with respect to the berry type was determined for tayberry-about $2 \%$ compared to the fresh state. Considering that freezing can exert a negative effect on certain bioactive components (vitamins, phenols, and anthocyanins) due to cell rupture, which in turn leads to decompartmentalization of antioxidants, and their interaction with oxidative enzymes, ultimately leading to a decrease in their content, but also due to the freezing effect of the release of bound bioactive compounds, this can have a positive effect on the antioxidant properties of foods. Still, the results are contradictory according to different literature; it is important to mention that certain important factors ultimately affect the bioactive compounds and thus the antioxidant properties of the same: type of plant food, product structure, and type of process used. For example, some studies have shown that freezing of whole fruits has no or very little effect, compared to puree or juices [16,56-58]; others showed that liquid nitrogen freezing observed no change in the concentration of bioactive compounds, as well as other freezing methods that involve the use of lower temperatures in the shortest possible time [10,59]. As expected, during the storage period, a decrease in antioxidant capacity was observed in both the frozen and classically frozen samples. The most significant decrease during storage was observed in frozen blackberry fruits, about $10 \%$ in frozen samples and about $7 \%$ in classically frozen samples. The obtained results are as expected and in agreement with other literature data, where a significant decrease in antioxidant activity during storage time was found $[17,60]$. 


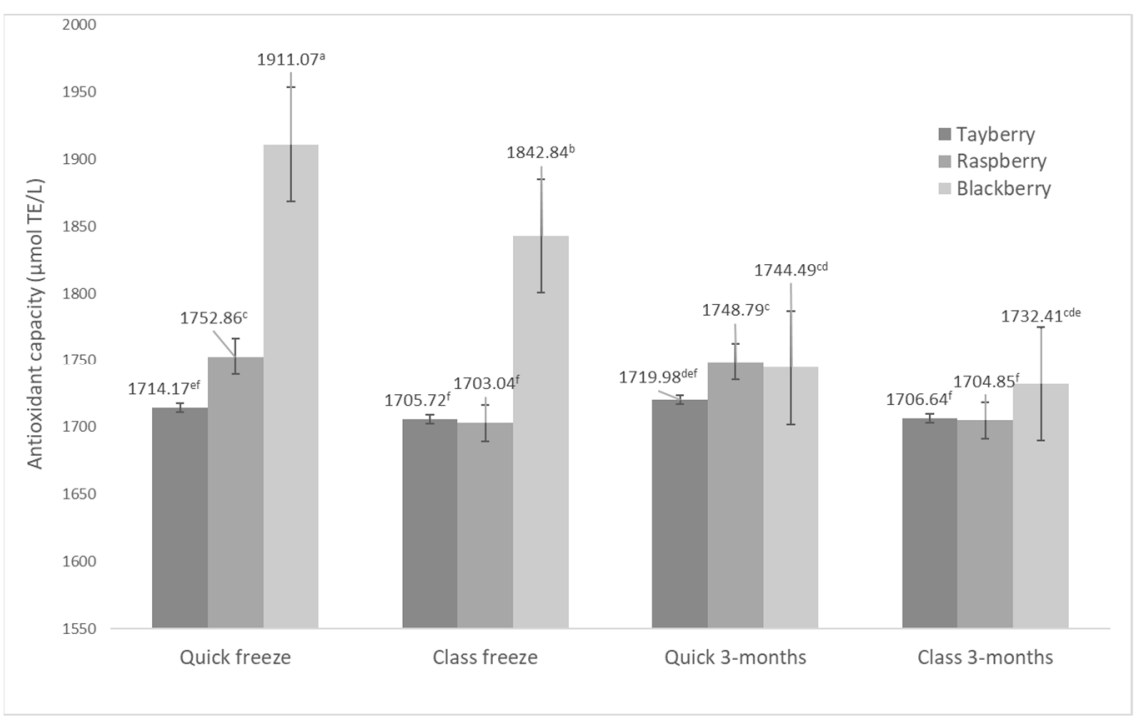

Figure 3. Antioxidant capacity ( $\mu \mathrm{mol} \mathrm{TE} / \mathrm{L}$ ) of frozen berry fruits and after storage, depending on the freezing method. Different letters indicate significant differences between mean values at $p \leq 0.0001$. Significance of interaction: $\mathrm{V} \times \mathrm{F}$-variety and freezing method $p \leq 0.7530 ; \mathrm{V} \times \mathrm{S}$-variety and storage $p \leq 0.0001 ; \mathrm{F} \times \mathrm{S}$-freezing method and storage $p \leq 0.8837 ; \mathrm{V} \times \mathrm{F} \times \mathrm{S}$ - variety, freezing method and storage $p \leq 0.0001$.

\section{Conclusions}

The studies carried out allow us to conclude that freezing, as a technological process, generally has a minor impact on the degradation of the content of bioactive substances (vitamins, phenols, anthocyanins) and effectively contributes to maintaining the quality of the final product. The selection of an appropriate freezing method is extremely important to maintain the nutritional quality of the product, and freezing temperature and duration are key factors in optimizing the appropriate method. The type of raw material to be frozen is also an important factor in process optimization, and ultimately the structure of the fruit (texture) has a significant influence on the selection of basic freezing parameters. The quick-freezing process, respectively lower freezing temperatures, and higher freezing rates $\left(-34^{\circ} \mathrm{C}, 25 \mathrm{~min}\right)$ contributed significantly to the preservation of berry fruit phytochemicals, i.e., bioactive compounds: Ascorbic acid, total phenols, anthocyanins, and thus the total antioxidant capacity of berries compared to classical freezing $\left(-18^{\circ} \mathrm{C}, 24 \mathrm{~h}\right)$. The external characteristics of the berry fruits, color and texture, changed less during freezing, focusing on the significantly lower drip loss after thawing and the color deterioration observed in the fruits frozen by the quick-freezing method, compared to the classical method. In general, it can be concluded that the quick-freezing method is extremely effective in preserving the nutritional quality of soft fruits. Future research should focus on more detailed analyzes of individual compounds using developed analytical methods (HPLC) in order to gain a deeper insight into the influence of freezing parameters on maintaining the quality of the final product.

Author Contributions: Conceptualization, J.Š.Ž. and S.V.; methodology, J.Š.Ž., S.V. and N.M.; formal analysis, J.Š.Ž., L.D. and A.G.; investigation, J.Š.Ž., S.V., L.D. and B.D.; data curation, A.G., B.D. and N.M.; writing —original draft preparation, J.Š.Ž. and S.V.; writing—review and editing, B.D., A.G. and N.M.; visualization, J.Š.Ž.; supervision, S.V.; project administration, S.V., N.M. and B.D. All authors have read and agreed to the published version of the manuscript.

Funding: This research received no external funding.

Institutional Review Board Statement: Not applicable. 
Informed Consent Statement: Not applicable.

Conflicts of Interest: The authors declare no conflict of interest.

\section{References}

1. Tumbas Šaponjac, V.T.; Ćetković, G.S.; Stajčić, S.M.; Vulić, J.J.; Čanadanović-Brunet, J.M.; Djilas, S.M. Optimization of the bioactive compounds content in raspberry during freeze-drying using response surface method. Chem. Ind. Chem. Eng. Q. 2015, $21,53-61$. [CrossRef]

2. Zorzi, M.; Gai, F.; Medana, C.; Aigotti, R.; Morello, S.; Peiretti, P.G. Bioactive Compounds and Antioxidant Capacity of Small Berries. Foods 2020, 9, 623. [CrossRef]

3. Rotelli, A.E.; Guardia, T.; Juárez, A.O.; De La Rocha, N.E.; Pelzer, L.E. Comparative study of flavonoids in experimental models of inflammation. Pharmacol. Res. 2003, 48, 601-606. [CrossRef]

4. Szajdek, A.; Borowska, E.J. Bioactive Compounds and Health-Promoting Properties of Berry Fruits: A Review. Plant Foods Hum. Nutr. 2008, 63, 147-156. [CrossRef] [PubMed]

5. Skrovankova, S.; Sumczynski, D.; Mlcek, J.; Jurikova, T.; Sochor, J. Bioactive Compounds and Antioxidant Activity in Different Types of Berries. Int. J. Mol. Sci. 2015, 16, 24673-24706. [CrossRef]

6. Ganhão, R.; Pinheiro, J.; Tino, C.; Faria, H.; Gil, M.M. Characterization of Nutritional, Physicochemical, and Phytochemical Composition and Antioxidant Capacity of Three Strawberry "Fragaria $\times$ ananassa Duch." Cultivars ("Primoris", "Endurance", and "Portola") from Western Region of Portugal. Foods 2019, 8, 682. [CrossRef] [PubMed]

7. Stamenković, Z.; Pavkov, I.; Radojčin, M.; Horecki, A.T.; Kešelj, K.; Kovačević, D.B.; Putnik, P. Convective Drying of Fresh and Frozen Raspberries and Change of Their Physical and Nutritive Properties. Foods 2019, 8, 251. [CrossRef]

8. Celli, G.B.; Ghanem, A.; Brooks, M.S.-L. Influence of freezing process and frozen storage on the quality of fruits and fruit products. Food Rev. Int. 2015, 32, 280-304. [CrossRef]

9. Neri, L.; Faieta, M.; Di Mattia, C.; Sacchetti, G.; Mastrocola, D.; Pittia, P. Antioxidant Activity in Frozen Plant Foods: Effect of Cryoprotectants, Freezing Process and Frozen Storage. Foods 2020, 9, 1886. [CrossRef]

10. Mullen, W.; Stewart, A.J.; Lean, M.E.J.; Gardner, P.; Duthie, G.G.; Crozier, A. Effect of Freezing and Storage on the Phenolics, Ellagitannins, Flavonoids, and Antioxidant Capacity of Red Raspberries. J. Agric. Food Chem. 2002, 50, 5197-5201. [CrossRef]

11. Leong, S.Y.; Oey, I. Effects of processing on anthocyanins, carotenoids and vitamin C in summer fruits and vegetables. Food Chem. 2012, 133, 1577-1587. [CrossRef]

12. Ketata, M.; Desjardins, Y.; Ratti, C. Effect of liquid nitrogen pretreatments on osmotic dehydration of blueberries. J. Food Eng. 2012, 116, 202-212. [CrossRef]

13. Alfaro, L.; Siramard, S.; Chouljenko, A.; Sathivel, S. Effects of liquid nitrogen pretreatment on the osmotic dehydration and quality of cryogenically frozen blueberries (Vaccinium angustifolium Ait.). Food Biosci. 2018, 22, 165-169. [CrossRef]

14. Yanat, M.; Baysal, T. Effect of freezing rate and storage time on quality parameters of strawberry frozen in modified and home type freezer. Croat. J. Food Technol. Biotechnol. Nutr. 2018, 13, 154-158. [CrossRef]

15. Cheng, L.; Wu, W.; An, K.; Xu, Y.; Yu, Y.; Wen, J.; Wu, J.; Zou, Y.; Liu, H.; Zhu, J.; et al. Advantages of Liquid Nitrogen Quick Freezing Combine Gradient Slow Thawing for Quality Preserving of Blueberry. Crystals 2020, 10, 368. [CrossRef]

16. González, E.M.; De Ancos, B.; Cano, M.P. Relation between bioactive compounds and free radical-scavenging capacity in berry fruits during frozen storage. J. Sci. Food Agric. 2003, 83, 722-726. [CrossRef]

17. Poiana, M.A.; Moigradean, D.; Raba, D.; Alda, L.M.; Popa, M. The effect of long-term frozen storage on the nutraceutical compounds, antioxidant properties and color indices of different kinds of berries. J. Food Agric. Environ. 2010, 8, 54-58.

18. Khattab, R.; Celli, G.B.; Ghanem, A.; Brooks, M.S.-L. Effect of frozen storage on polyphenol content and antioxidant activity of haskap berries (Lonicera caerulea L.). J. Berry Res. 2015, 5, 231-242. [CrossRef]

19. Xie, J.; Zhao, Y. Use of vacuum impregnation to develop high quality and nutritionally fortified frozen strawberries. J. Food Process. Preserv. 2004, 28, 117-132. [CrossRef]

20. AOAC. Official Methods of Analysis, 16th ed.; Association of Official Analytical Chemists: Washington, DC, USA, 1995.

21. AOAC. Official Methods of Analysis, 17th ed.; Association of Official Analytical Chemists: Washington, DC, USA, 2002.

22. Ough, C.S.; Amerine, M.A. Methods for Analysis of Musts and Wines; John Wiley \& Sons: New York, NJ, USA, 1988.

23. Miller, N.J.; Diplock, A.T.; Rice-Evans, C.; Davies, M.J.; Gopinathan, V.; Milner, A. A novel method for measuring antioxidant capacity and its application to monitoring the antioxidant status in premature neonates. Clin. Sci. 1993, 84, 407-412. [CrossRef]

24. SAS Institute. SAS®/STAT 9.3; SAS Institute Inc.: Cary, NC, USA, 2011.

25. Vergara, M.F.; Vargas, J.; Acuña, J.F. Physicochemical characteristics of blackberry (Rubus glaucus Benth.) fruits from four production zones of Cundinamarca, Colombia. Agron. Colomb. 2016, 34, 336-345. [CrossRef]

26. Ponder, A.; Świetlikowska, K.; Hallmann, E. The qualitative evaluation of the fruit of individual cultivars Rubus taking into account their usefulness to organic farming. J. Agric. Eng. Res. 2017, 62, 99-102.

27. Pantelidis, G.; Vasilakakis, M.; Manganaris, G.; Diamantidis, G. Antioxidant capacity, phenol, anthocyanin and ascorbic acid contents in raspberries, blackberries, red currants, gooseberries and Cornelian cherries. Food Chem. 2007, 102, 777-783. [CrossRef]

28. Viskelis, P.; Bobinaite, R.; Rubinskiene, M.; Sasnauskas, A.; Lanauskas, J. Chemical Composition and Antioxidant Activity of Small Fruits. In Horticulture; Maldonado, A.I.L., Ed.; InTech Open: Rijeka, Croatia, 2012; pp. 75-102. 
29. Purgar, D.D.; Duralija, B.; Voća, S.; Vokurka, A.; Ercisli, S. A Comparison of Fruit Chemical Characteristics of Two Wild Grown Rubus Species from Different Locations of Croatia. Molecules 2012, 17, 10390-10398. [CrossRef] [PubMed]

30. Hunterlab, H.L. a, b Color Scale. Applications Note 8(9). 2012. Available online: http://www.hunterlab.se/wp-content/uploads/ 2012/11/Hunter-L-a-b.pdf (accessed on 15 June 2021).

31. Chen, Y.; Martynenko, A. Combination of hydrothermodynamic (HTD) processing and different drying methods for natural blueberry leather. LWT-Food Sci. Technol. 2018, 87, 470-477. [CrossRef]

32. Palonen, P.; Weber, C. Fruit color stability, anthocyanin content, and shelf life were not correlated with ethylene production rate in five primocane raspberry genotypes. Sci. Hortic. 2018, 247, 9-16. [CrossRef]

33. Vieira, L.M.; Marinho, L.M.G.; Rocha, J.D.C.G.; Barros, F.A.R.; Stringheta, P.C. Chromatic analysis for predicting anthocyanin content in fruits and vegetables. Food Sci. Technol. 2019, 39, 415-422. [CrossRef]

34. Dhalaria, R.; Verma, R.; Kumar, D.; Puri, S.; Tapwal, A.; Kumar, V.; Nepovimova, E.; Kuca, K. Bioactive Compounds of Edible Fruits with Their Anti-Aging Properties: A Comprehensive Review to Prolong Human Life. Antioxidants 2020, 9, 1123. [CrossRef] [PubMed]

35. Ochoa-Velasco, C.E.; Avila-Sosa, R.; Navarro-Cruz, A.R.; López-Malo, A.; Palou, E. Biotic and Abiotic Factors to Increase Bioactive Compounds in Fruits and Vegetables. In Handbook of Food Bioengineering; Grumezescu, A.M., Holban, A.M., Eds.; Elsevier: Amsterdam, The Netherlands, 2017; Volume 2, pp. 317-349. [CrossRef]

36. Toscano, S.; Trivellini, A.; Cocetta, G.; Bulgari, R.; Francini, A.; Romano, D.; Ferrante, A. Effect of Preharvest Abiotic Stresses on the Accumulation of Bioactive Compounds in Horticultural Produce. Front. Plant Sci. 2019, 10, 1212. [CrossRef] [PubMed]

37. Croge, C.P.; Cuquel, F.L.; Pintro, P.T.; Biasi, L.A.; De Bona, C.M. Antioxidant Capacity and Polyphenolic Compounds of Blackberries Produced in Different Climates. HortScience 2019, 54, 2209-2213. [CrossRef]

38. Beekwilder, J.; Jonker, H.; Meesters, P.; Hall, R.D.; van der Meer, A.I.M.; de Vos, C.H.R. Antioxidants in Raspberry: On-Line Analysis Links Antioxidant Activity to a Diversity of Individual Metabolites. J. Agric. Food Chem. 2005, 53, 3313-3320. [CrossRef] [PubMed]

39. Casas-Forero, N.; Orellana-Palma, P.; Petzold, G. Influence of block freeze concentration and evaporation on physicochemical properties, bioactive compounds and antioxidant activity in blueberry juice. Food Sci. Technol. 2020, 40, 387-394. [CrossRef]

40. Allan-Wojtas, P.; Goff, H.D.; Stark, R.; Carbyn, S. The effect of freezing method and frozen storage conditions on the microstructure of wild blueberries as observed by cold-stage scanning electron microscopy. Scanning 2006, 21, 334-347. [CrossRef]

41. Adamczak, A.; Buchwald, W.; Kozłowski, J.; Mielcarek, S. The effect of thermal and freeze drying on the content of organic acids and flavonoids in fruit of European cranberry (Oxycoccus palustris Pers.). Herb. Pol. 2009, 55, 94-102.

42. Ikegaya, A.; Ohba, S.; Nakajima, T.; Toyoizumi, T.; Ito, S.; Arai, E. Practical long-term storage of strawberries in refrigerated containers at ice temperature. Food Sci. Nutr. 2020, 8, 5138-5148. [CrossRef]

43. Wrolstad, R.E.; Putnam, T.P.; Varseveld, G.W. Color quality of frozen strawberries: Effect of anthocyanin, ph, total acidity and ascorbic acid variability. J. Food Sci. 1970, 35, 448-452. [CrossRef]

44. De Ancos, B.; Sánchez-Moreno, C.; Pascual-Teresa, S.; Cano, M.P. Freezing preservation of fruits. In Handbook of Fruits and Fruit Processing, 2nd ed.; Sinha, N., Sidhu, J.S., Barta, J., Wu, J.S.B., Cano, M.P., Eds.; John Wiley \& Sons: Oxford, UK, $2012 ;$ pp. 103-119.

45. Sahari, M.A.; Boostani, F.M.; Hamidi, E.Z. Effect of low temperature on the ascorbic acid content and quality characteristics of frozen strawberry. Food Chem. 2004, 86, 357-363. [CrossRef]

46. Ceballos, A.M.; Giraldo, G.I.; Orrego, C. Effect of freezing rate on quality parameters of freeze dried soursop fruit pulp. J. Food Eng. 2012, 111, 360-365. [CrossRef]

47. Dawson, P.; Al-Jeddawi, W.; Rieck, J. The Effect of Different Freezing Rates and Long-Term Storage Temperatures on the Stability of Sliced Peaches. Int. J. Food Sci. 2020, 2020, 1-17. [CrossRef] [PubMed]

48. Turkben, C.; Sarıburun, E.; Demir, C.; Uylaşer, V.; Sariburun, E. Effect of Freezing and Frozen Storage on Phenolic Compounds of Raspberry and Blackberry Cultivars. Food Anal. Methods 2009, 3, 144-153. [CrossRef]

49. Bakowska-Barczak, A.M.; Kolodziejczyk, P.P. Black currant polyphenols: Their storage stability and microencapsulation. Ind. Crop. Prod. 2011, 34, 1301-1309. [CrossRef]

50. Holzwarth, M.; Korhummel, S.; Carle, R.; Kammerer, D.R. Evaluation of the effects of different freezing and thawing meth-ods on color, polyphenol and ascorbic acid retention in strawberries (Fragaria $\times$ ananassa Duch.). Food Res. Int. 2012, 48, 241-248. [CrossRef]

51. Rickman, J.C.; Barrett, D.M.; Bruhn, C.M. Nutritional comparison of fresh, frozen and canned fruits and vegetables. Part 1. Vitamins C and B and phenolic compounds. J. Sci. Food Agric. 2007, 87, 930-944. [CrossRef]

52. Reque, P.M.; Steffens, R.S.; Jablonski, A.; Flores, S.; Rios, A.D.O.; de Jong, E.V. Cold storage of blueberry (Vaccinium spp.) fruits and juice: Anthocyanin stability and antioxidant activity. J. Food Compos. Anal. 2014, 33, 111-116. [CrossRef]

53. Manzocco, L.; Calligaris, A.S.; Nicoli, M.C. Modeling Bleaching of Tomato Derivatives at Subzero Temperatures. J. Agric. Food Chem. 2006, 54, 1302-1308. [CrossRef]

54. Syamaladevi, R.; Sablani, S.S.; Tang, J.; Powers, J.; Swanson, B.G. Stability of Anthocyanins in Frozen and Freeze-Dried Raspberries during Long-Term Storage: In Relation to Glass Transition. J. Food Sci. 2011, 76, E414-E421. [CrossRef]

55. Veberic, R.; Stampar, F.; Schmitzer, V.; Cunja, V.; Zupan, A.; Koron, D.; Mikulic-Petkovsek, M. Changes in the Contents of Anthocyanins and Other Compounds in Blackberry Fruits Due to Freezing and Long-Term Frozen Storage. J. Agric. Food Chem. 2014, 62, 6926-6935. [CrossRef] 
56. Lohachoompol, V.; Srzednicki, G.; Craske, J. The Change of Total Anthocyanins in Blueberries and Their Antioxidant Effect After Drying and Freezing. J. Biomed. Biotechnol. 2004, 2004, 248-252. [CrossRef] [PubMed]

57. Gonçalves, G.A.S.; Resende, N.S.; Carvalho, E.; de Resende, J.V.; Boas, E.V.D.B.V. Effect of pasteurisation and freezing method on bioactive compounds and antioxidant activity of strawberry pulp. Int. J. Food Sci. Nutr. 2017, 68, 682-694. [CrossRef] [PubMed]

58. Bulut, M.; Bayer, Ö.; Kırtıl, E.; Bayındırlı, A. Incidence de la vitesse de congélation et de la durée d'entreposagesur les paramètres de texture et de qualité de fraises et de haricots verts congelés dans un dans un congélateur domestique. Int. J. Refrig. 2018, 88, 360-369. [CrossRef]

59. Patthamakanokporn, O.; Puwastien, P.; Nitithamyong, A.; Sirichakwal, P.P. Changes of antioxidant activity and total phenolic compounds during storage of selected fruits. J. Food Compos. Anal. 2008, 21, 241-248. [CrossRef]

60. Kopjar, M.; Tiban, N.N.; Pilizota, V.; Babic, J. Stability of anthocyanins, phenols and free radical scavenging activity through sugar addition during frozen storage of blackberries. J. Food Process. Preserv. 2009, 33, 1-11. [CrossRef] 